\title{
Monitoring of Carbon Sequestration in Iceland Using Remote Sensing Technology: An Overview of the LanDeg Project ${ }^{+}$
}

\author{
Michaela Hrabalikova ${ }^{1, *}$ and David C. Finger ${ }^{2}$ \\ 1 All for Soil (Vse pro pudu, z.s.), Sokolovska 1853/153, 18000 Prague, Czech Republic \\ 2 School of Science and Engineering, Reykjavik University, Menntavegur, 101 Reykjavik, Iceland; \\ davidf@ru.is \\ * Correspondence: hrabalikova@allforsoil.com \\ † Presented at TERRAenVISION 2019, Barcelona, Spain, 2-7 September 2019.
}

Published: 24 December 2019

\begin{abstract}
The monitoring of restoration and forestation is essential to reduce future drought and flood risk as well as ongoing carbon sequestration projects in Iceland. This is especially relevant for Iceland's efforts to become carbon neutral by 2040 . Such a monitoring can be done by using the state-of-art remote sensing technology, using remotely sensed data and digital mapping approaches. The LanDeg project will use free Geographic Information System (GIS) and Remote Sensing (RS) data to map soil degradation, restoration and ongoing forestation efforts to assess carbon sequestration. For this purpose, we will validate GIS and RS data analysis with field mapping of vegetation and soil cover in a restored area in southern Iceland. The validated GIS and RS analysis will be used to assess restoration efforts and trends in vegetation cover in the area. Subsequently, the changes in the vegetation cover will be used to assess the carbon sequestration rate. Based on these results we will identify best-restoration and carbon sequestration practices.
\end{abstract}

Keywords: soil degradation; surface runoff; reclamation; reforestation

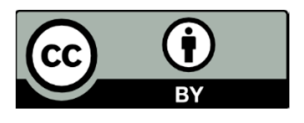

(C) 2019 by the authors. Licensee MDPI, Basel, Switzerland. This article is an open access article distributed under the terms and conditions of the Creative Commons Attribution (CC BY) license (http://creativecommons.org/licenses/by/4.0/). 